\title{
Exploring family activities and child engagement: a study on children with a significant cognitive and motor developmental delay
}

\begin{abstract}
Background: Everyday activities are an important setting for stimulating child functioning, but are understudied in young children with a significant cognitive and motor developmental delay. Therefore, we aim to characterize their family activities in terms of diversity, frequency, child engagement and family member's presence, compared to typically developing children.

Methods: By asking a parent to fill out an adapted version of the Child Participation in Family Activities questionnaire, the activity pattern of 49 children within the study group and 45 children within the control group were assessed and compared.

Results: Children in the study group generally experience less diverse activities (with an additional lower frequency of out-of-home activities) and show lower engagement levels compared to typically developing children.

Conclusions: Incorporating high levels of personal interaction, highly stimulating activities and adapted leisure activities into the daily activity pattern of children with multiple disabilities might be a pathway to increased engagement levels.
\end{abstract}

Keywords: family activities; child engagement; severe and multiple disabilities; profound and multiple disabilities 


\section{Introduction}

Children's functioning is shaped by their experiences within different interrelated layers of social contexts that surround them. The most proximal, and most influential setting is formed by the child's parents and the family context (Lochman, 2004). Beyond genetic endowment, parent's behavior within parent-child interaction is a principal stimulus to children's development (Bornstein, 2001). However, by orchestrating a series of experiences that extend beyond the intimate parent-child relationship, parents can contribute further to their child's development (Dunst et al., 2001; Guralnick, 2011; Mahoney \& Nam, 2011). Especially during the early childhood period, parents take responsibility for organizing a myriad of home and community experiences (Guralnick, 2005). These experiences might be developmentally beneficial, not only by reinforcing and extending parent-child interactions, but also by introducing the child to the many demands created by different participants and settings (Guralnick, 2011). As long as children are actively engaged, they have the potential to learn meaningful information from each activity or interaction they have throughout their day (Kim \& Mahoney, 2004). In line with this view, Granlund et al. (2012) regard the participation of children in family activities as twofold: the child's presence (i.e. being physically there) and the child's engagement (i.e. expression of involvement).

Most studies have focused on children with physical disabilities, mild developmental delays or combined children with various levels and types of disabilities (Taheri, Perry, \& Minnes, 2016), resulting in generalized conclusions on heterogeneous groups. However, very little is known on the specific target group of children with a significant cognitive and motor developmental delay (Van keer \& Maes, 2018). The combination of the significant motor and cognitive limitations provides the child as well as the parent with specific challenges, because of the dynamic influences between these and other developmental domains (Fagnart, 2011; McCollum, 2002) as well as additional practical and emotional barriers. For example, parents need to invest a lot of time in physical care tasks and support activities for their child with multiple and complex needs and may still be in the acceptance process, potentially disrupting the otherwise natural and spontaneous course of everyday activity (Brett, 2004; Luijkx, van der Putten, \& Vlaskamp, 2017; Tadema \& Vlaskamp, 2009). Also, there is a great need for people in the child's proximal environment to 
act as 'scene-setters', i.e. to arrange opportunities for child participation (Axelsson, Imms, \& Wilder, 2014). Nevertheless, despite all barriers, everyday activities remain an important setting for supporting and strengthening child competence (Dunst et al., 2001). A study of Arthur (2004) on behavior states in students (4-18 years) with profound and multiple disabilities suggests that providing activities can elicit higher levels of engagement in these children throughout the day, thus increasing their learning opportunities. In previous research of Axelsson and Wilder (2014) on children (aged 5-20 years) with profound intellectual and multiple disabilities (PIMD), reported child presence in family activities was consistently lower compared to typically developing children (except for a few physically less demanding activities), predominantly with regard to out-of-home activities. Similarly, parents within the PIMD-group generally reported lower child engagement, however, in both groups child engagement was highest in child-driven activities and lowest in routine activities (Axelsson, Granlund, \& Wilder, 2013). The children's presence in activities was positively correlated with their motor ability (Axelsson \& Wilder, 2014), while the child's engagement was positively related to the child's cognitive functioning (Axelsson et al., 2013). Influencing factors at the family level were less pronounced in the PIMD-group than in typically developing children. A higher educational level and (primarily) a higher family income were related to a higher frequency of only a limited number of activities (e.g. going on vacation, Axelsson \& Wilder, 2014), and were not associated to higher child engagement in family activities (Axelsson et al., 2013).

Although the studies by Axelsson and colleagues provide a highly valuable insight into the family activities of an understudied population, they are characterized by a wide age range in which no information is collected on the youngest group of children (i.e. below 5 years of age). Bult, Verschuren, Jongmans, Lindeman and Ketelaar (2011) indicate that, in research on daily activities, there is a general shortage of information on children of pre-school age. Therefore, this study aims to characterize the family activities in young children (6 months - 4 years) with a significant cognitive and motor developmental delay in terms of (1) diversity, (2) frequency, (3) child engagement and (4) family member's presence, in comparison with typically developing children. Based on previous research (in higher age ranges), we generally expect lower 
levels of diversity, frequency and engagement in the DD-group compared to the TD-group, although less pronounced in home-based activities compared to out-of-home activities with regard to the first two factors.

\section{Method}

\subsection{Participant criteria}

Two groups of participants were included: children with a significant cognitive and motor developmental delay (DD-group) and typically developing children (TD-group). Both groups consisted of children between the chronological age of 6 and 59 months. We did not include children before the age of 6 months because, in the DD-group, clear indications of a significant developmental delay should be present and we wanted to respect the high emotional stress of parents in the first months after birth.

A significant cognitive delay was operationalized using the 'Tandemlijst' (Stadeus, Windey, Vermier, \& Van Driessche, 1994). In the DD-group, we included children functioning below a quarter of their chronological age, which is associated with the description of a profound intellectual disability (Grossman, 1973; Hogg, Foxen, \& McBrien, 1981; Vig \& Sanders, 2007). The Tandemlijst is specifically developed for young children with a developmental delay. It includes the developmental steps and milestones used in early intervention programs. By describing the cognitive developmental domain separately and in detail, the influence of the motor limitations on the estimation of cognitive functioning is minimized as much as possible. A significant motor delay was operationalized using the 'Gross Motor Function Classification System - Expanded \& Revised' (GMFCS-E\&R; Palisano, Rosenbaum, Bartlett, \& Livingston, 2007). The GMFCS is specifically developed for and widely used in research on relatively young children with significant motor limitations and shows a good reliability and predictive value (Wood \& Rosenbaum, 2000). Also, the instrument provides descriptions of motor abilities for different age bands, including 0 to 2,2 to 4 and 4 to 6 years. In the DD-group, we included children functioning at level IV or V (indicating a severe impairment) and, additionally, level III when the child was less than 2 years old (since combining level III, IV and V has a better predictive value at this young age; Gorter, Ketelaar, Rosenbaum, Helders, \& Palisano, 2009). Detailed inclusion criteria are available from the first author upon request. The 
presence of a significant developmental delay in both the cognitive and the motor domain was regarded as a necessary and sufficient inclusion criterion for the DD-group (Nakken \& Vlaskamp, 2007). Children who only showed a significant delay in one of the two domains were not included. We formulated no criteria regarding the cause of the developmental delay and the presence of additional constraints (sensory disabilities, health problems, comorbid diagnoses such as ASS, etc.). Children who were functioning within the age band corresponding to their chronological age, on the Tandemlijst as well as the GMFCS, were regarded as typically developing and therefore included in the TD-group.

\subsection{Recruitment}

The DD-group ( $n=49)$ was recruited by contacting more than 300 hospitals, diagnostic centers, early intervention teams and specialized day care centers in the Dutch-speaking part of Belgium as well as the Netherlands. The TD-group $(n=45)$ was recruited by randomly selecting 5 day care centers and 5 kindergartens within each of the 6 provinces within the Dutch-speaking part of Belgium. Professionals, directors and/or teachers within the contacted organizations were asked (by mail and/or by telephone) to inform potential participants on the study. It was communicated that this study was approved by the Social and Societal Ethics Committee (KU Leuven) and informed consent was obtained from parents prior to data collection. Participants could choose to fill out the questionnaire either electronically or on paper and were free to choose whether the mother or father participated as informant in the study. When two or more children within one family met the inclusion criteria, the participating parent was asked to fill out the questionnaire with regard to one child only.

\subsection{Sample characteristics}

Detailed background information on the children and their family context in both groups is presented in Table 1 . The group characteristics are generally comparable, although the typically developing children are somewhat younger and more often (still) an only child. This was expected, since we experienced that (parents of) children without disabilities are easier to reach at a young age. Also striking, mothers of typically developing children more often work part-time than full-time compared to the mothers in the DDgroup. 
In line with the studies of Anna Karin Axelsson, we define a family as "a unit that defines itself as a family, including individuals who are related by blood or marriage as well as those who have made a commitment to share their lives" (Hanson \& Linch, 2004, p. 5). However, we did only include family members who were living with the child. In case of reconstituted families (i.e. when the child experiences family activities in two different family units), data was collected on only one of the family units (i.e. the family unit of the informant). In all cases, this was the family unit in which the child spends the most time. The 49 families in the DD-group typically consist of a mother, a (step)father and one or more child(ren). In 3 of the families, there is a single mother and in 12 of the families, the participating child is the only child. The 45 families in the TD-group typically consist of a (step)mother, a (step)father and one or more children. In 1 of the families, there is a single father and in 19 of the families, the participating child is the only child. Also, in 2 families, there are two mothers and in 1 family, the child's grandparents take up the parental role. For convenience, male and female parental figures are further referred to as fathers and mothers respectively.

The typically developing children generally spent their weekdays in a daycare or preschool, but this is often complemented by a (couple of) day(s) at home or with family. Their evenings and weekends are spent within the family unit or sporadically with family or friends. Most of the children with a developmental delay spent their weekdays in a specialized daycare, facility or school; complemented by a (couple of) day(s) at home. Approximately a fifth of the children spent most of their weekdays at home. Caretaking by family seems less evident in this group. These children's evenings and weekends are also generally spent within the family unit or sporadically with family or friends. However, most of the children are occasionally brought to a specialized organization or another child-minding family for short stays in order to relieve the parents.

[Insert Table 1]

\subsection{Instrument}


Family activities were assessed using an adapted version of the Child Participation in Family Activities (Child-PFA) questionnaire, developed for families of children (aged 0-20 years) with profound intellectual and multiple disabilities (Axelsson et al., 2013). In an effort to ensure construct validity, the original questionnaire has been developed through inspection of similar instruments aimed at other populations, researcher's discussion seminars as well as a pilot study, incorporating parent's feedback. An exploratory factor analysis found most factor loadings to be above .3, while the questionnaire is also reported to be characterized by good internal consistency (Cronbach's Alpha's above .8). Within the Child-PFA, a family activity was defined as a daily life activity in which more than one family member takes part. Adaptations to the original questionnaire were driven by the specific focus of this study (e.g. sole focus on family activities in which the particular child is present), the embedding of this study in a larger longitudinal project (e.g. time intervals were set at 6 months), substantive considerations (e.g. distinction between paying and getting a visit, distinction in frequency between 'never' and 'less than monthly') and cultural differences (e.g. the item 'going to church' was removed). An overview of all adaptations is available from the first author upon request. In our study, parents were presented with a list of 58 family activities, organized into six activity domains: indoor activities $(n=18)$, meals $(n=7)$, routines $(n=8)$, outdoor activities $(n=11)$, organized activities $(n=4)$ and outings $(n=10)$. For each activity, within the time frame of the past six months, the parent was asked (1) how often the activity occurred when the particular child was present, (2) who is usually present next to the particular child and (3) how engaged the child tends to be during the activity. The frequency of the activities was rated on a 5-point Likert scale, ranging from 'never' to 'daily'. Parents could indicate whether a sibling and (one of) the parents was usually present during the specific activity. When rating the child's engagement on a 4-point Likert scale ranging from 'not at all' to 'much', we asked parents to keep in mind the child's usual level of attention, enthusiasm and active participation in relation to the specific activity.

\subsection{Data analysis}


To provide a detailed characterization of the family activities in terms of frequency, children's engagement and family member's presence, descriptive statistics (median scores with interquartile range for the former two characteristics and group proportions for the latter) are presented for each group at item level (cf. Table 2). For frequency and engagement levels, Mann-Whitney U tests are used to identify which group reported significantly higher scores. We propose a non-parametric test because of the small sample size and the presence of non-normality in the data. For family members, we also report the average group proportions at category level. Importantly, all group proportions are corrected for the possible presence of a family member. This means that the denominator in the calculation is not only corrected for non-frequency of the activity (because information on family member's presence evidently did not have to be reported) and missing data, but also for one-parent households or same-sex couples (for the data on mothers and fathers) and one-child households (for the data on siblings). For example, in 27 of 39 DD-children that are reported to watch TV as a family activity, a sibling is reported to be usually present. However, 11 of these 39 families are one-child households. Therefore, sibling presence is reported to be .96 (27/28) instead of .69 (27/39).

Further, general characteristics of family activities (diversity, frequency, family member's presence and child engagement) are analyzed at category level (cf. Table 3 to 6). The more detailed information in Table 2 will be used to interpret the results of these analyses. For the analysis of diversity, we take into account the raw number of activities with a reported frequency higher than zero, reporting the mean number (also converted to a proportion) and standard deviation within each group. Group means are then compared using a Mann-Whitney $U$ test. For the analysis of frequency levels and child engagement, participant's scores (i.e. zero to four and zero to three, respectively) are added up within each category and divided by the number of (reported) activities within that category. The mean and standard deviation of these results are reported for each group and compared using a Mann-Whitney U test. For a more detailed analysis of family member's presence, we look at specific types or combinations of members: 'one parent', 'two parents', 'one or more sibling(s)' and 'one or more parent(s) plus one or more sibling(s)'. Average group 
proportions (and corresponding standard deviation) are reported at category level, also corrected for the possible presence of a (combination of) family member(s).

Effect sizes $|r|$ are calculated by dividing the Z-statistic by the square root of $N$ (Cohen, 1988; Fritz, Morris, \& Richler, 2012). For interpretation of effect sizes, we will follow the guidelines of Cohen (1988), regarding 0.5 as a large effect, 0.3 as an intermediate effect and 0.1 as a small effect. A priori power-analysis (using G*Power 3.1; Faul, Erdfelder, Lang, \& Buchner, 2007) with a specified power of 0.8 (Moore \& McCabe, 2005) reveals that the sample size allows for a reliable detection of large and medium, but not small group differences. In the DD-group, missing data levels were $0.28 \%$ for frequency, $1.34 \%$ for child engagement and $1.48 \%$ for family member's presence. To conduct our analyses, we used a pairwise deletion strategy, adapting the denominators in the analyses if necessary. No missing data was present in the TDgroup since participants within this group all filled out the questionnaire electronically (cf. forced responses). All analyses were performed with SPSS Statistics 25.0 (IBM Corp, 2017).

\section{Results}

In Table 2, we provide median frequency levels, median engagement levels and the proportion of participants in which a given individual family member was present in a specific activity. This information at item-level will be used to further interpret the results at category-level, with regard to diversity (cf. Table 3), frequency (cf. Table 4), child engagement (cf. Table 5) and family member's presence (cf. Table 6). [Insert Table 2 to 6 ]

\subsection{General overview}

In both groups, the reported diversity is the highest for routines and the lowest for organized activities. However, the diversity is significantly higher in the TD-group for all categories, except for 'organized activities'. The effect sizes for 'indoor activities', 'meals', 'routines' and 'outdoor activities' are all rather large (with the latter two showing the largest effect size), while the effect size for 'outings' is more intermediate. Similar results are found with regard to the mean frequency of the activities, however, these results are heavily influenced by the activities with a reported frequency of zero. The corrected means also 
show that the reported frequency is the highest for 'routines' and the lowest for 'organized activities'. However, the TD-group only scores significantly higher for 'outdoor activities' and 'outings', characterized by an intermediate effect size. In both groups, children are the least engaged in meal-related activities. The highest engagement levels are elicited by 'indoor activities' in the DD-group and by 'outings' in the TDgroup. Children in the TD-group are reported to show significantly higher levels of engagement in all categories, characterized by (very) high effect sizes. Based on visual inspection, both groups show the same pattern with regard to the presence of family members. On average, when possible, activities within all categories are usually attended by one or more parent(s) and one or more sibling(s). If not, activities are more often attended by two parents instead of one. The sole presence of (a) sibling(s) is not often reported, especially not with regard to meals, routines and outings. Overall, mothers are more often present than fathers. This result is most pronounced with regard to meals and routines, in both groups. For meals and outdoor activities, this result is more pronounced in the TD-group compared to the DD-group.

\subsection{Indoor activities}

With regard to the 18 questioned indoor activities, the TD-group reports a greater average diversity (75\% compared to $60 \%$ in the DD-group) with a rather high effect size. However, the mean frequency of the reported activities (cf. corrected means) is comparable in both groups. At item-level, we notice that the frequency of watching movies or TV, singing with/to the child, listening to music and playing with siblings is high and comparable among the two groups; while the frequency of playing computer/tablet games, other computer-related activities and playing instruments is also comparable, but low. Activities that require higher levels of cognitive or motor functioning, such as handicraft, board games, book-related activities and dancing, occur strikingly more often in the TD-group. However, the latter two are still reported at a median frequency of 3 and 2 in the DD-group, which suggests that parents might adapt these activities to the child's functioning (e.g. using picture books or holding the child while dancing). A higher frequency in the TDgroup is also evident for playing with parents, other adults, other children and pets as well as joking and fooling around. Children in the DD-group almost never play with other children or pets. The only activity that occurs significantly more often in the DD-group is exercising physical therapy at home, which does 
seldom occur in the TD-group. Children in the TD-group generally show greater engagement in indoor activities (with a very high effect size of .71), but this is not the case for playing computer/tablet games, playing instruments and listening to music. The highest engagement levels in the DD-group are elicited by playing with persons (except children outside the core family) and music-related activities. The general findings with regard to family member's presence apply, but activities in this category are the ones that are most often attended by (a) sibling(s) only compared to the other categories.

\subsection{Meals}

With regard to the 7 questioned meal-related activities, the TD-group reports a greater average diversity ( $88 \%$ compared to $61 \%$ in the DD-group) with a rather high effect size. However, the mean frequency of the reported activities (cf. corrected means) is comparable in both groups. At item-level, we notice that the frequency of having a drink, lunch and dinner together is high and comparable among the two groups. Having breakfast together as well as more organizational activities such as cooking/baking, doing the dishes and laying/cleaning the table occur more often in the TD-group, with intermediate to high effect sizes. Strikingly more variation is notable in the frequency of having lunch together in the DD-group compared to the TD-group, possibly related to the children's daytime activities. Children in the TD-group show greater engagement in all meal-related activities (with high effect sizes ranging from .47 to .67), although levels are generally low. Children in the DD-group even show no engagement at all in the more organizational activities. The mother is almost always present at activities within this category. Also, the higher presence of mothers compared to fathers is notably more pronounced in the TD-group.

\subsection{Routines}

With regard to the 8 questioned routine-related activities, the TD-group reports a strikingly greater average diversity (98\% compared to $77 \%$ in the DD-group) with a high effect size. However, the mean frequency of the reported activities (cf. corrected means) is comparable in both groups. At item-level, we notice that the frequency of morning and evening routines, nursing activities and transportation by car is high and comparable among the two groups. More organizational activities, such as packing a school/day bag, picking up after playing and cleaning the house, occur strikingly more often in the TD-group, with high 
effect sizes. Children in the TD-group show greater engagement in all routine-related activities (with rather high effect sizes ranging from .40 to .68). Children in the DD-group are most engaged in nursing activities, compared to the other items. Within this category, in both groups, the mother is almost always present and the higher presence of mothers compared to fathers is the most striking compared to other categories.

\subsection{Outdoor activities}

With regard to the 11 questioned outdoor activities, the TD-group reports a strikingly greater average diversity (80\% compared to 55\% in the DD-group) with a high effect size. Also, the mean frequency of the reported activities (cf. corrected means) is higher in the TD-group, with an intermediate effect size. At item-level, we notice that the frequency of going for a walk is high and comparable among the two groups; while the frequency of going shopping, going on a swing and playing outside with siblings is also comparable, but this happens more sporadically. Shopping for groceries, gardening, bicycling, playing in the sandpit and playing outside with the parents, other adults or other children occurs more often in the TDgroup, with intermediate to high effect sizes. Children in the TD-group show greater engagement in all outdoor activities (with rather high effect sizes ranging from .40 to .76). Children in the DD-group are most engaged in going on a swing and bicycling (although the latter happens very rarely), compared to the other items. The general findings with regard to family member's presence apply, but the higher presence of mothers compared to fathers is notably more pronounced in the TD-group.

\subsection{Organized activities}

With regard to the 4 questioned organized activities, the diversity in the TD- and DD-group is comparable (36\% and 37\% respectively). Also, the mean frequency of the reported activities (cf. corrected means) is comparable in both groups. At item-level, we notice that going to own, family member's or center/school-related leisure activities is very rare in both groups. Going to the parent's leisure activity does happen more frequently in the TD-group with an intermediate effect size. When these types of activities do happen, children in the TD-group show greater engagement (with intermediate to high effect sizes ranging from .36 to .76). Children in the DD-group are most engaged in their own leisure activities. Whenever possible, the mother is almost always present at activities within this category. 


\subsection{Outings}

With regard to the 10 questioned outings, the TD-group reports a greater average diversity (82\% compared to $73 \%$ in the DD-group) with an intermediate effect size. Also, the mean frequency of the reported activities (cf. corrected means) is higher in the TD-group, with an intermediate effect size. At itemlevel, we notice that the frequency of going to the theater/cinema/concert, going to parties and going on vacation is low and comparable among the two groups. Visits from or of friends happen sporadically, but also with a comparable frequency in both groups. Going to the library and the playground, going out in the nature as well as visits from or of relatives occur more often in the TD-group, with intermediate effect sizes. Children in the TD-group show greater engagement in all outings (with rather high effect sizes ranging from .41 to .77). Children in the DD-group are most engaged in receiving visits from relatives and going on vacation, compared to the other items. Whenever possible, the mother is almost always present at activities within this category.

\section{Discussion}

\subsection{Conclusions}

In this study, we aimed to characterize family activities in young children (6-59 months) within six categories (i.e. indoor activities, meals, routines, outdoor activities, organized activities and outings) with regard to diversity, frequency, child engagement and family member's presence. A great deal of the reported diversity and frequency levels can be expected based on the children's young age (e.g. low frequency of going to the theater/cinema/concert vs. high frequency of nursing activities) or the type of activity (e.g. low frequency of vacation vs. high frequency of having dinner). However, the results show further differences within and between the two studied groups (i.e. children with a significant cognitive and motor developmental delay and typically developing children). Generally, the data confirmed our hypothesis that children with a significant cognitive and motor developmental delay experience less diverse activities and show lower engagement levels compared to typically developing children. The results with regard to the frequency of the activities are more nuanced: when looking at the activities that are reported (i.e. frequency 
higher than zero), only 'outdoor activities' and 'outings' have a higher frequency in typically developing children. This confirms our expectation to find less pronounced differences in home-based activities compared to out-of-home activities, possibly related to practical barriers such as transportation (Axelsson \& Wilder, 2014; Raghavendra, Virgo, Olsson, Connell, \& Lane, 2011) and/or child-related factors such as the more difficult adaptation of the activity to the child's functioning and preferences. Visits from or to friends are reported equally often in both groups, while visits from or to relatives occur less often in children with a significant developmental delay. In the comparable study of Axelsson and Wilder (2014), where the DD-group consisted of children with PIMD between 5 and 20 years old, a significant difference in contact with both groups (friends and relatives) was found. Previous research on children with developmental disabilities in general has also shown that parents have less frequent contact with their friends over time compared to parents of TD-children (Mailick-Seltzer, Greenberg, Floyd, Pette, \& Hong, 2001). It might be possible that, due to the young age of the children in our study group, a gradual decrease in contact with friends has not yet taken place. The lower frequency of visiting relatives is harder to explain: it might be that these types of visits often coincide with babysitting arrangements, which might be less evident in the DD-group as previously suggested. Getting or paying a visit does not make any difference in terms of frequency, which might suggest that practical barriers do not play a role in these types of social visits. Further, it stands out that indoor activities elicit the highest engagement level in children with a significant developmental delay, while typically developing children are most engaged during outings. Notably, with regard to specific activities, children with a significant DD are most engaged when playing with persons indoor (including joking and fooling around), during nursing activities, music-related activities, highly stimulating activities such as going on a swing or bicycling; and when going to their own leisure activity (possibly because this is adapted to their own needs and preferences). Globally, most of these activities are characterized by personal, one-to-one interaction (playing with someone, nursing) and/or strong stimuli (music, fooling around, going on a swing, bicycling). So, next to pointing out the children's need for and enjoyment of personal interaction, these results confirm previous research suggesting that combining multiple stimuli might elicit higher levels of responding in children with multiple disabilities (Neerinckx, 
2015; Van keer et al., 2019). Strikingly, some of the activities that elicit the highest engagement levels are only reported by a small fraction of the study group, possibly because of the need for affordable and adapted materials (i.e. a special swing or bike) and a lack of adapted leisure activities (especially at this young age). Few differences are found between the two groups with regard to family member's presence: mostly the activities are attended by one or more parent(s) and one or more sibling(s). If not, activities are more often attended by two parents instead of one. In general, mothers are more often present than fathers.

\subsection{Strengths and Limitations}

The greatest merit of the current study is the focus on an understudied topic (i.e. family activities) in an understudied population (i.e. children with a significant cognitive and motor developmental delay). We gathered information in a fairly large study group, included a control group and made use of a questionnaire that is specifically adapted to the target group and characterized by good internal consistency, all of which is hard to achieve in research on persons with profound intellectual and multiple disabilities. Since the adaptations made to the questionnaire were either minor or aimed at obtaining a more detailed picture of the family's activity pattern, we do not expect these to have had a major impact on the instrument's validity or reliability. However, since a psychometric analysis of the questionnaire was outside the scope of this study, we cannot draw robust conclusions on this topic. Further, we tried to take into account the differences in family situation between participants by examining the comparability of the study and control group on a myriad of background factors and taking into account the possible presence of specific family members in the analyses. However, the study's results need to be interpreted with caution.

For one, the non-randomized sampling method impedes generalizability. Since we primarily recruited participants indirectly through professionals, we were probably not able to reach children that stay at home full-time and our insight into a possible selection bias as well as the reasons behind nonparticipation is fairly limited. Secondly, the questionnaire covers a wide range of family activities, but is not exhaustive. For example, parents often mentioned 'swimming' as a relevant activity that was not included. Also, some parents wanted to provide information on specific activities that were not separately questioned but might be part of a broader item (e.g. taking a bath), mostly because they felt these activities 
elicited high engagement levels in their child. Further, the subdivision of frequency categories ('never' to 'daily' on a 5 point Likert scale) is rather broad and might obscure more subtle differences in frequency levels. Lastly, results might differ according to the time point on which parents filled out the questionnaire due to the defined time frame of six months and related seasonal changes in activity schedule.

\subsection{Suggestions for Further Research}

Firstly, this study adopts a very specific focus on the child's core family unit since young children (especially when they have a significant developmental delay) are highly dependent upon their parents and typically spend most of their time within this unit. However, the child also usually spends a significant amount of waking hours in other contexts, such as a day care or at school. Therefore, characterizing the activities that are offered to the children in these other contexts is a valuable recommendation for further studies. Also, further research should go beyond mere characterization and try to uncover the relation of these activities with child functioning and well-being.

Secondly, previous research has identified the level of motor as well as cognitive functioning as important influencing variables (Bult et al., 2011). Within our specific target group, no diagnostic instruments are currently available to make a reliable distinction in level of cognitive and motor functioning within this young age group. Therefore, we recommend incorporating two additional control groups in further studies, including children with a singular cognitive and a singular motor developmental delay. We attempted to incorporate these multiple control groups into the current study, but did not reach a sufficient sample size. Therefore, we recommend intensive international collaboration or long-term partnerships with relevant services to ensure sufficient participant recruitment.

Thirdly, we have uncovered differences in family activities in terms of diversity and frequency between as well as within the study and control group. However, we do not have a clear view on the reasons behind these differences. On the one hand, relevant variables such as children's age, children's gender, family income and parent's educational level could be incorporated statistically. On the other hand, 
qualitative research is warranted in which parents are asked about how and why they organize certain family activities and what barriers and facilitators they experience.

Lastly, we recommend a strong focus by professionals on guiding families in the organization of their activities, since this can stimulate everyday natural learning opportunities for young children with a significant cognitive and motor developmental delay. One of the participating parents indicated that filling out the questionnaire 'opened her eyes'. As a working mother, she felt she had very little time to undertake family activities. However, the list of activities within the questionnaire pointed out that she took a lot of ordinary, daily activities for granted when they actually provide a myriad of opportunities for meaningful interaction with her child. To conclude, more attention could be paid to the organization of adapted leisure activities for children within our target group.

\section{References}

Arthur, M. (2004). Patterns amongst behavior states, sociocommunicative, and activity variables in educational programs for students with profound and multiple disabilities. Journal of Developmental and Physical Disabilities, 16(2), 125-149.

Axelsson, A.K., Granlund, M. \& Wilder, J. (2013). Engagement in family activities: a quantitative, comparative study of children with profound intellectual and multiple disabilities and children with typical development. Child: Care, Health and Development, 39(4) 523-534.

Axelsson, A. K., Imms, C., \& Wilder, J. (2014). Strategies that facilitate participation in family activities of children and adolescents with profound intellectual and multiple disabilities: parents' and personal assistants' experiences. Disability and Rehabilitation, 36(25), 2169-2177.

Axelsson, A.K. \& Wilder J. (2014). Frequency of occurrence and child presence in family activities: a comparative study of children with profound intellectual and multiple disabilities and children with typical development. International Journal of Developmental Disabilities, 60(1), 13-25.

Bornstein, M. H. (2001). Parenting: Science and practice. Parenting, 1(1-2), 1-4. 
Running Head: FAMILY ACTIVITIES AND CHILD ENGAGEMENT

Brett, J. (2004). The journey to accepting support: How parents of profoundly disabled children experience support in their lives. Paediatric Nursing, 16(8), 14-8.

Bult, M. K., Verschuren, O., Jongmans, M. J., Lindeman, E., \& Ketelaar, M. (2011). What influences participation in leisure activities of children and youth with physical disabilities? A systematic review. Research in developmental disabilities, 32(5), 1521-1529.

Cohen, J. (1988). Statistical Power Analysis for the Behavioral Sciences, 2nd Edition. Hillsdale: Lawrence Erlbaum.

Dunst, C. J., Bruder, M. B., Trivette, C. M., Hamby, D., Raab, M., \& McLean, M. (2001). Characteristics and consequences of everyday natural learning opportunities. Topics in Early childhood special education, 21(2), 68-92.

Fagnart, D. (2011). Bewegingsbeperkingen. In: Maes, B., Vlaskamp, C., \& Penne, A. (Eds.), Ondersteuning van mensen met ernstige meervoudige beperkingen. Handvatten voor een kwaliteitsvol leven. Acco, Leuven.

Faul, F., Erdfelder, E., Lang, A. G., \& Buchner, A. (2007). G* Power 3: A flexible statistical power analysis program for the social, behavioral, and biomedical sciences. Behavior research methods, 39(2), $175-191$.

Fritz, C. O., Morris, P. E., \& Richler, J. J. (2012). Effect size estimates: current use, calculations, and interpretation. Journal of Experimental Psychology: General, 141(1), 2.

Gorter, J. W., Ketelaar, M., Rosenbaum, P., Helders, P. J., \& Palisano, R. (2009). Use of the GMFCS in infants with CP: the need for reclassification at age 2 years or older. Developmental Medicine \& Child Neurology, 51(1), 46-52.

Granlund, M., Arvidsson, P., Niia, A., Björck-Åkesson, E., Simeonsson, R., Maxwell, G., ... \& Pless, M. (2012). Differentiating activity and participation of children and youth with disability in Sweden: a third qualifier in the International Classification of Functioning, Disability, and Health for Children and Youth?. American Journal of Physical Medicine \& Rehabilitation, 91(13), S84-S96. 
Grossman, H. J. (1973). Manual on Terminology and Classification in Mental Retardation. American Association on Mental Deficiency: Special Publication Series, No. 2. Washington D.C.: American Association on Mental Deficiency.

Guralnick, M. J. (2005). Early intervention for children with intellectual disabilities: Current knowledge and future prospects. Journal of Applied Research in Intellectual Disabilities, 18(4), 313-324.

Guralnick, M. J. (2011). Why early intervention works: A systems perspective. Infants and young children, 24(1), 6 .

Hanson, M.J., \& Lynch, E.W. (2004). Understanding families: Approaches to diversity, disability, and risk. Baltimore: P.H. Brookes.

Hogg, J., Foxen, T., \& McBrien, J. (1981). Issues in the training and evaluation of behaviour modification skills for staff working with profoundly retarded multiply handicapped children. Behavioural Psychotherapy (New Series), 9(04), 345-357.

IBM Corp. Released 2017. IBM SPSS Statistics for Windows, Version 25.0. Armonk, NY: IBM Corp.

Kim, J. M., \& Mahoney, G. (2004). The Effects of Mother's Style of Interaction on Children's Engagement Implications for Using Responsive Interventions with Parents. Topics in Early Childhood Special Education, 24(1), 31-38. doi: 10.1177/02711214040240010301

Lochman, J. E. (2004). Contextual factors in risk and prevention research. Merrill-Palmer Quarterly, 50(3), 311-325.

Luijkx, J., van der Putten, A. A. J., \& Vlaskamp, C. (2017). Time use of parents raising children with severe or profound intellectual and multiple disabilities. Child: Care, Health and Development, 43(4), 518526.

Mahoney, G., \& Nam, S. (2011). The parenting model of developmental intervention. International review of research on mental retardation, 41, 73-125.

Mailick-Seltzer, M., Greenberg, J., Floyd, F., Pette, Y., \& Hong, J. (2001). Life course impact of parenting a child with a disability. American Journal on Mental Retardation, 106, 265-286. 
McCollum, J. A. (2002). Influencing the development of young children with disabilities: Current themes in early intervention. Child and Adolescent Mental Health, 7(1), 4-9.

Moore, D.S. and McCabe, G. (2005). Introduction to the Practice of Statistics, fifth edition. Gordonsville: W. H. Freeman Publishers.

Nakken, H., \& Vlaskamp, C. (2007). A need for a taxonomy for profound intellectual and multiple disabilities. Journal of Policy and Practice in intellectual Disabilities, 4(2), 83-87.

Neerinckx, H. (2015). Need time: Joint attention in interactions with people with profound intellectual and multiple disabilities (Doctoral dissertation). Leuven: K.U. Leuven, Onderzoekseenheid Gezins- en orthopedagogiek.

Palisano, R., Rosenbaum, P., Bartlett, D., \& Livingston, M. (2007). Gross Motor Function Classification System: Expanded and Revised. CanChild Centre for Childhood Disability Research, McMaster University.

Raghavendra, P., Virgo, R., Olsson, C., Connell, T., \& Lane, A. E. (2011). Activity participation of children with complex communication needs, physical disabilities and typically-developing peers. Developmental Neurorehabilitation, 14(3), 145-155.

Stadeus, A., Windey, K., Vermeir, G., \& Van Driessche, S. (1994). Tandemlijst voor jonge kinderen met ontwikkelingsmoeilijkheden. Leuven: Garant.

Tadema, A. C., \& Vlaskamp, C. (2009). The time and effort in taking care for children with profound intellectual and multiple disabilities: A study on care load and support. British Journal of Learning Disabilities, 38, 41-48.

Taheri, A., Perry, A., \& Minnes, P. (2016). Examining the social participation of children and adolescents with Intellectual Disabilities and Autism Spectrum Disorder in relation to peers. Journal of Intellectual Disability Research, 60(5), 435-443.

Van keer, I., Ceulemans, E., Bodner, N., Vandesande, S., Van Leeuwen, K., \& Maes, B. (2019). Parentchild interaction: A micro-level sequential approach in children with a significant cognitive and 
Running Head: FAMILY ACTIVITIES AND CHILD ENGAGEMENT

motor developmental delay. Research in Developmental Disabilities, 85, 172-186. https://doi.org/10.1016/j.ridd.2018.11.008

Van keer, I., \& Maes, B. (2018). Contextual factors influencing the developmental characteristics of young children with severe to profound intellectual disability: A critical review. Journal of Intellectual \& Developmental Disability, 43(2), 183-201. DOI: 10.3109/13668250.2016.1252458

Vig, S., \& Sanders, M. (2007). Assessment of Mental Retardation. In Brassard, M. R., \& Boehm, A. E. (Eds.) Preschool assessment: Principles and practices. Guilford Press.

Wood, E., \& Rosenbaum, P. (2000). The gross motor function classification system for cerebral palsy: a study of reliability and stability over time. Developmental Medicine and Child Neurology, 42, 29296. 


\section{Table 1}

\section{Sample Characteristics}

\begin{tabular}{|c|c|c|c|c|c|c|}
\hline \multirow[t]{2}{*}{ Variables } & \multicolumn{3}{|c|}{ DD-group } & \multicolumn{3}{|c|}{ TD-group } \\
\hline & $N(\%)$ & min.-max. & $M(S D)$ & $N(\%)$ & $\min .-\max$ & $M(S D)$ \\
\hline Families & 49 & & & 45 & & \\
\hline Number of family members & & $2-8$ & $3.96(.98)$ & & $2-6$ & $3.84(.93)$ \\
\hline Parent(al figure)s & & $1-2$ & $1.96(.20)$ & & $1-2$ & $1.98(.15)$ \\
\hline Children & & $1-6$ & $2.00(.94)$ & & $1-4$ & $1.87(.89)$ \\
\hline One-parent households & $3(6 \%)$ & & & $1(2 \%)$ & & \\
\hline Reconstituted families & $3(6 \%)$ & & & $5(11 \%)$ & & \\
\hline \multicolumn{7}{|l|}{ Country of residence } \\
\hline Belgium & $26(53 \%)$ & & & $49(100 \%)$ & & \\
\hline The Netherlands & $23(47 \%)$ & & & $0(0 \%)$ & & \\
\hline Children & 49 & & & 45 & & \\
\hline \multicolumn{7}{|l|}{ Gender } \\
\hline Male & $21(43 \%)$ & & & $26(58 \%)$ & & \\
\hline Female & $28(57 \%)$ & & & $19(42 \%)$ & & \\
\hline Age (in months) & & $12-58$ & $38.11(10.85)$ & & $7-54$ & $24.86(11.54)$ \\
\hline \multicolumn{7}{|l|}{ Sensory impairments } \\
\hline Reduced vision & $19(38 \%)$ & & & $0(0 \%)$ & & \\
\hline Blindness & $2(4 \%)$ & & & $0(0 \%)$ & & \\
\hline Reduced hearing & $1(2 \%)$ & & & $0(0 \%)$ & & \\
\hline Deafness & $2(4 \%)$ & & & $0(0 \%)$ & & \\
\hline \multicolumn{7}{|l|}{ Health problems } \\
\hline Gastro-intestinal problems & $26(53 \%)$ & & & $0(0 \%)$ & & \\
\hline Heart problems & $1(2 \%)$ & & & $0(0 \%)$ & & \\
\hline Respiratory problems & $10(20 \%)$ & & & $1(2 \%)$ & & \\
\hline Epilepsy & $28(57 \%)$ & & & $0(0 \%)$ & & \\
\hline Others & $10(20 \%)$ & & & $2(4 \%)$ & & \\
\hline \multicolumn{7}{|l|}{ Etiology } \\
\hline Genetic defect & $25(51 \%)$ & & & NA & & \\
\hline Perinatal asphyxia & $3(6 \%)$ & & & NA & & \\
\hline Acquired brain injury & $3(6 \%)$ & & & NA & & \\
\hline Unknown & $18(37 \%)$ & & & NA & & \\
\hline
\end{tabular}




\begin{tabular}{|c|c|c|c|c|c|c|}
\hline \multirow[t]{2}{*}{ Variables } & \multicolumn{3}{|c|}{ DD-group } & \multicolumn{3}{|c|}{ TD-group } \\
\hline & $N(\%)$ & min.-max. & $M(S D)$ & $N(\%)$ & min.-max & $M(S D)$ \\
\hline \multicolumn{7}{|l|}{ Parity } \\
\hline Firstborn & $23(47 \%)$ & & & $26(58 \%)$ & & \\
\hline Only child & $12(24 \%)$ & & & $19(42 \%)$ & & \\
\hline Parent(al figure)s & 95 & & & 89 & & \\
\hline Male ("Fathers") & $46(48 \%)$ & & & $43(48 \%)$ & & \\
\hline Age (in years) ${ }^{\mathrm{a}}$ & & $26-54$ & $36.43(5.94)$ & & $24-52$ & $34.55(5.55)$ \\
\hline \multicolumn{7}{|l|}{ Highest educational level ${ }^{\mathrm{b}}$} \\
\hline Primary education & $4(10 \%)$ & & & $3(8 \%)$ & & \\
\hline Secondary education & $17(41 \%)$ & & & $17(46 \%)$ & & \\
\hline Higher education & $20(49 \%)$ & & & $17(46 \%)$ & & \\
\hline \multicolumn{7}{|l|}{ Activity status ${ }^{\mathrm{b}}$} \\
\hline Working full-time & $34(83 \%)$ & & & $36(97 \%)$ & & \\
\hline Working part-time & $4(10 \%)$ & & & $0(0 \%)$ & & \\
\hline (Consciously) unemployed & $3(7 \%)$ & & & $1(3 \%)$ & & \\
\hline Female ("Mothers") & $49(52 \%)$ & & & $46(52 \%)$ & & \\
\hline Age $\left(\right.$ in years) ${ }^{\mathrm{c}}$ & & $26-42$ & $34.52(4.17)$ & & $21-45$ & $32.07(4.88)$ \\
\hline \multicolumn{7}{|l|}{ Highest educational level $^{\mathrm{d}}$} \\
\hline Primary education & $1(2 \%)$ & & & $1(2 \%)$ & & \\
\hline Secondary education & $17(35 \%)$ & & & $21(47 \%)$ & & \\
\hline Higher education & $31(63 \%)$ & & & $23(51 \%)$ & & \\
\hline \multicolumn{7}{|l|}{ Activity status ${ }^{\mathrm{d}}$} \\
\hline Working full-time & $12(24 \%)$ & & & $29(64 \%)$ & & \\
\hline Working part-time & $25(51 \%)$ & & & $9(20 \%)$ & & \\
\hline (Consciously) unemployed & $12(24 \%)$ & & & $7(16 \%)$ & & \\
\hline
\end{tabular}

${ }^{\mathrm{a}}$ This information was missing for 4 fathers in the DD-group and 5 fathers in the TD-group

${ }^{\mathrm{b}}$ This information was missing for 5 fathers in the DD-group and 6 fathers in the TD-group (percentages were calculated based on $n=41$ and $n=37$ )

${ }^{\mathrm{c}}$ This information was missing for 5 mothers in the DD-group and 4 mothers in the TD-group

${ }^{\mathrm{d}}$ This information was missing for 1 mother in the TD-group (percentages were calculated based on $n=45$ ) 
Table 2

Frequency, Child Engagement and Family Member's Presence on Item Level in the DD-group and the TD-group

\begin{tabular}{|c|c|c|c|c|c|c|c|c|c|c|c|c|}
\hline & \multicolumn{2}{|c|}{$\begin{array}{c}\text { Frequency }^{\mathbf{a}} \\
\mathrm{Q}_{2}\left(\mathrm{Q}_{1}-\mathrm{Q}_{3}\right)\end{array}$} & \multirow[t]{3}{*}{$|r|^{\mathrm{e}}$} & \multicolumn{2}{|c|}{$\begin{array}{c}\text { Engagement }^{\mathbf{b}} \\
\mathrm{Q}_{2}\left(\mathrm{Q}_{1}-\mathrm{Q}_{3}\right)\end{array}$} & \multirow[t]{3}{*}{$|r|^{\mathrm{e}}$} & \multicolumn{6}{|c|}{$\begin{array}{c}\text { Family member's presence } \\
\text { Group proportions }{ }^{\mathrm{d}}\end{array}$} \\
\hline & \multirow{2}{*}{$\mathrm{DD}$} & \multirow{2}{*}{ TD } & & \multirow{2}{*}{$\mathrm{DD}$} & \multirow{2}{*}{$\mathrm{TD}$} & & \multicolumn{3}{|c|}{ DD } & \multicolumn{3}{|c|}{ TD } \\
\hline & & & & & & & $\mathrm{M}$ & $\mathrm{F}$ & $\mathrm{S}$ & $\mathrm{M}$ & $\mathrm{F}$ & $\mathrm{S}$ \\
\hline Watching movie(s) & $4(1-4)$ & $3(2.5-4)$ & & $1(1-2)$ & $2(1.5-3)^{*}$ & .34 & 0.87 & 0.83 & 1.00 & 0.93 & 0.88 & 0.79 \\
\hline Watching TV & $4(3-4)$ & $4(3-4)$ & & $1(1-2)$ & $2(2-3)^{*}$ & .51 & 0.90 & 0.86 & 0.96 & 0.95 & 0.92 & 0.75 \\
\hline Joking and fooling around & $4(4-4)$ & $4(4-4)^{*}$ & .27 & $2(1-2)$ & $3(3-3)^{*}$ & .65 & 0.95 & 0.93 & 0.78 & 0.98 & 0.93 & 0.77 \\
\hline Playing games on computer/tablet & $0(0-2.5)$ & $0(0-2)$ & & $1(0-2)$ & $2(0.5-2)$ & & 0.59 & 0.35 & 0.64 & 0.76 & 0.81 & 0.71 \\
\hline Other computer-related activities & $0(0-2.5)$ & $0(0-2)$ & & $0(0-0.5)$ & $1(0-2)^{*}$ & .40 & 0.92 & 0.75 & 0.38 & 0.55 & 0.65 & 0.31 \\
\hline Doing handicraft & $0(0-1.5)$ & $2(1-3)^{*}$ & .42 & $1(0-1)$ & $2(2-3)^{*}$ & .65 & 0.75 & 0.28 & 0.79 & 0.87 & 0.43 & 0.59 \\
\hline Playing board games & $0(0-0.5)$ & $2(0-2.5) *$ & .40 & $0(0-1)$ & $2(1-3)^{*}$ & .52 & 0.91 & 1.00 & 1.00 & 0.87 & 0.77 & 0.62 \\
\hline Playing with parent(s) & $4(3.25-4)$ & $4(4-4)^{*}$ & .25 & $2(1-2)$ & $3(2-3)^{*}$ & .53 & 0.98 & 0.90 & 0.78 & 1.00 & 0.93 & 0.69 \\
\hline Playing with other adult(s) & $1.5(0-3)$ & $3(2-3) *$ & .29 & $2(1-2)$ & $3(2-3)^{*}$ & .57 & 0.62 & 0.65 & 0.68 & 0.69 & 0.56 & 0.75 \\
\hline Playing with sibling(s) & $3(0-4)$ & $3(0-4)$ & & $2(1-2)$ & $3(3-3)^{*}$ & .63 & 0.45 & 0.46 & 1.00 & 0.72 & 0.64 & 1.00 \\
\hline Playing with other child(ren) & $0(0-2)$ & $2(0-3)^{*}$ & .21 & $1(0.25-2)$ & $3(2-3)^{*}$ & .60 & 0.75 & 0.58 & 0.83 & 0.87 & 0.71 & 0.71 \\
\hline Playing with pets & $0(0-0)$ & $3(0-4)^{*}$ & .51 & $1(0.5-2)$ & $2(2-3)^{*}$ & .47 & 1.00 & 0.50 & 0.80 & 0.90 & 0.77 & 0.84 \\
\hline Playing instrument(s) & $0(0-2.5)$ & $1(0-3)$ & & $2(1-3)$ & $2(1-3)$ & & 0.73 & 0.59 & 0.57 & 0.93 & 0.88 & 0.82 \\
\hline Listening to music & $4(3-4)$ & $4(3-4)$ & & $2(1-2.25)$ & $2(2-3)$ & & 0.93 & 0.83 & 0.64 & 0.95 & 0.83 & 0.85 \\
\hline Dancing & $2(0-3)$ & $3(3-4) *$ & .60 & $1(1-2)$ & $3(2-3) *$ & .55 & 0.90 & 0.76 & 0.63 & 0.93 & 0.58 & 0.85 \\
\hline Exercising physical therapy at home & $0(0-3)^{*}$ & $0(0-0)$ & .40 & $2(1-2)$ & $1(0-1)$ & & 0.62 & 0.35 & 0.07 & 1.00 & 0.50 & 0.50 \\
\hline Meals & & & & & & & 0.98 & 0.80 & 0.66 & 0.97 & 0.73 & 0.64 \\
\hline Cooking/baking & $3(0-4)$ & $4(2.5-4) *$ & .29 & $0(0-0)$ & $1(1-2)^{*}$ & .64 & 0.93 & 0.44 & 0.32 & 0.97 & 0.67 & 0.50 \\
\hline Doing the dishes & $0(0-4)$ & $4(1-4)^{*}$ & .33 & $0(0-0)$ & $1(0-1.25)^{*}$ & .47 & 0.94 & 0.67 & 0.31 & 0.94 & 0.70 & 0.50 \\
\hline Laying the table/cleaning away & $0(0-4)$ & $4(3-4)^{*}$ & .43 & $0(0-0)$ & $1(1-2)^{*}$ & .67 & 1.00 & 0.75 & 0.50 & 1.00 & 0.79 & 0.54 \\
\hline Having a drink together & $3(0-4)$ & $3(2-4)$ & & $1(0-1)$ & $2(1-3)^{*}$ & .58 & 1.00 & 0.93 & 0.80 & 1.00 & 0.69 & 0.61 \\
\hline Having breakfast together & $4(0-4)$ & $4(3.5-4) *$ & .21 & $1(1-2)$ & $3(2-3)^{*}$ & .53 & 1.00 & 0.94 & 0.88 & 0.98 & 0.74 & 0.80 \\
\hline Having lunch together & $3(0-4)$ & $3(3-3)$ & & $1(1-2)$ & $3(2-3)^{*}$ & .65 & 1.00 & 0.85 & 0.85 & 0.93 & 0.68 & 0.75 \\
\hline Having dinner together & $4(3-4)$ & $4(4-4)$ & & $1(1-2)$ & $3(2-3)^{*}$ & .67 & 0.98 & 1.00 & 0.97 & 0.98 & 0.86 & 0.77 \\
\hline Routines & & & & & & & 0.97 & 0.69 & 0.51 & 0.99 & 0.69 & 0.64 \\
\hline Cleaning the house & $0(0-4)$ & $4(4-4)^{*}$ & .55 & $0(0-0)$ & $1(1-2)^{*}$ & .55 & 1.00 & 0.65 & 0.53 & 1.00 & 0.66 & 0.58 \\
\hline Doing morning routines & $4(4-4)$ & $4(4-4)$ & & $1(1-2)$ & $3(2-3) *$ & .50 & 1.00 & 0.64 & 0.41 & 1.00 & 0.58 & 0.62 \\
\hline
\end{tabular}




\begin{tabular}{|c|c|c|c|c|c|c|c|c|c|c|c|c|}
\hline Doing evening routines & $4(4-4)$ & $4(4-4)$ & & $1(1-2.25)$ & $3(2-3)^{*}$ & .50 & 1.00 & 0.79 & 0.43 & 0.98 & 0.84 & 0.62 \\
\hline Nursing activities & $4(4-4)$ & $4(4-4)$ & & $2(1-3)$ & $3(2-3)^{*}$ & .46 & 0.96 & 0.75 & 0.40 & 0.98 & 0.84 & 0.62 \\
\hline Packing school/day bag & $1(0-4)$ & $4(3.5-4)^{*}$ & .42 & $0(0-0)$ & $1(0-1.5)^{*}$ & .40 & 0.96 & 0.43 & 0.41 & 1.00 & 0.36 & 0.36 \\
\hline Picking up after playing & $1(0-4)$ & $4(4-4)^{*}$ & .52 & $0(0-0)$ & $1(1-3)^{*}$ & .68 & 1.00 & 0.57 & 0.59 & 1.00 & 0.76 & 0.62 \\
\hline Going by car to/from school/daycare & $3.5(3-4)$ & $4(3-4)$ & & $1(1-2)$ & $2(2-3)^{*}$ & .44 & 0.83 & 0.74 & 0.52 & 0.98 & 0.59 & 0.84 \\
\hline Going by car at other occasions & $3(3-3)$ & $3(3-4)$ & & $1(1-2)$ & $2(2-3) *$ & .52 & 0.98 & 0.93 & 0.78 & 1.00 & 0.93 & 0.88 \\
\hline Outdoor activities & & & & & & & 0.79 & 0.72 & 0.68 & $\mathbf{0 . 8 8}$ & 0.73 & 0.71 \\
\hline Shopping for groceries & $3(1.5-3)$ & $3(3-3)^{*}$ & .28 & $1(0-1)$ & $2(2-3) *$ & .60 & 0.98 & 0.62 & 0.50 & 0.98 & 0.55 & 0.60 \\
\hline Going shopping & $2(1-2)$ & $2(1-2)$ & & $1(0-1)$ & $2(1-3)^{*}$ & .61 & 1.00 & 0.53 & 0.50 & 1.00 & 0.50 & 0.76 \\
\hline Playing outside with sibling(s) & $0(0-2)$ & $1(0-3.5)$ & & $1(0-1)$ & $3(3-3)^{*}$ & .76 & 0.63 & 0.67 & 1.00 & 0.83 & 0.78 & 1.00 \\
\hline Playing outside with other child(ren) & $0(0-1)$ & $2(0-3)^{*}$ & .39 & $1(0-1)$ & $3(2-3)^{*}$ & .69 & 0.54 & 0.58 & 0.73 & 0.91 & 0.57 & 0.65 \\
\hline Playing outside with parent(s) & $2(0-3)$ & $3(3-4)^{*}$ & .49 & $1(1-2)$ & $3(2-3)^{*}$ & .71 & 0.97 & 0.90 & 0.64 & 0.98 & 0.93 & 0.65 \\
\hline Playing outside with other adult(s) & $0(0-1)$ & $3(0-3)^{*}$ & .53 & $1(1-2)$ & $3(2-3)^{*}$ & .59 & 0.65 & 0.75 & 0.70 & 0.79 & 0.47 & 0.75 \\
\hline Going on a swing & $2(0-3)$ & $2(0-3)$ & & $2(1-3)$ & $3(3-3)^{*}$ & .40 & 0.83 & 0.83 & 0.76 & 0.94 & 0.87 & 0.65 \\
\hline Bicycling & $0(0-2)$ & $3(1-3)^{*}$ & .33 & $2(1-2)$ & $3(2-3)^{*}$ & .57 & 0.80 & 0.71 & 0.56 & 0.95 & 0.83 & 0.82 \\
\hline Going for a walk & $3(2-3)$ & $3(3-4)$ & & $1(1-2)$ & $3(2-3)^{*}$ & .58 & 1.00 & 0.77 & 0.74 & 0.95 & 0.93 & 0.88 \\
\hline Playing in the sandpit & $0(0-0)$ & $2(0-3)^{*}$ & .49 & $1(0.50-2)$ & $3(3-3)^{*}$ & .61 & 0.60 & 0.63 & 0.86 & 0.81 & 0.69 & 0.53 \\
\hline Going to child's leisure activity & $0(0-1)$ & $0(0-1)$ & & $2(1-2)$ & $2(2-3)^{*}$ & .36 & 0.89 & 0.76 & 0.43 & 1.00 & 0.62 & 0.82 \\
\hline Going to sibling's leisure activity & $0(0-1)$ & $0(0-1)$ & & $1(0-1)$ & $2(2-3)^{*}$ & .76 & 0.81 & 0.60 & 1.00 & 0.92 & 0.75 & 1.00 \\
\hline Going to parent's leisure activity & $0(0-0)$ & $0(0-1.5)^{*}$ & .29 & $1(0-1.5)$ & $2(1-3)^{*}$ & .53 & 1.00 & 1.00 & 0.50 & 1.00 & 0.83 & 0.70 \\
\hline Going to center/school activities & $1(0-1)$ & $0(0-1)$ & & $1(1-2)$ & $3(2-3) *$ & .63 & 0.97 & 0.76 & 0.67 & 1.00 & 0.95 & 0.79 \\
\hline Outings & & & & & & & 0.99 & 0.88 & 0.88 & 0.99 & 0.86 & 0.81 \\
\hline Going to the playground & $1(0-2)$ & $2(1-3)^{*}$ & .32 & $1(1-2)$ & $3(3-3)^{*}$ & .77 & 1.00 & 0.75 & 0.88 & 1.00 & 0.79 & 0.76 \\
\hline Going to the library & $0(0-0.5)$ & $0(0-1)^{*}$ & .21 & $0(0-0.75)$ & $2(1-3)^{*}$ & .62 & 0.92 & 0.50 & 0.73 & 0.95 & 0.29 & 0.53 \\
\hline Going to the theater/cinema/concert & $0(0-0)$ & $0(0-1)$ & & $0(0-2)$ & $2(0.75-3) *$ & .41 & 1.00 & 0.78 & 0.40 & 1.00 & 0.71 & 0.58 \\
\hline Visiting friends & $2(1-2)$ & $2(1.5-3)$ & & $1(1-2)$ & $2(2-3)^{*}$ & .63 & 1.00 & 0.95 & 1.00 & 1.00 & 0.95 & 0.88 \\
\hline Receiving a visit from friends & $2(1-2)$ & $2(1-2.5)$ & & $1(1-2)$ & $3(2-3)^{*}$ & .66 & 1.00 & 1.00 & 1.00 & 1.00 & 0.95 & 0.92 \\
\hline Visiting relatives & $2(2-3)$ & $3(3-3)^{*}$ & .43 & $1(1-2)$ & $3(2-3)^{*}$ & .70 & 0.98 & 0.91 & 1.00 & 1.00 & 0.98 & 0.92 \\
\hline Receiving a visit from relatives & $2(2-3)$ & $3(2-3)^{*}$ & .25 & $2(1-2)$ & $3(2-3)^{*}$ & .67 & 0.98 & 1.00 & 1.00 & 1.00 & 1.00 & 0.92 \\
\hline Going to parties & $1(0-1)$ & $1(1-2)$ & & $1(1-1)$ & $2(2-3)^{*}$ & .60 & 1.00 & 0.97 & 0.92 & 1.00 & 1.00 & 0.87 \\
\hline Going out in the nature & $2(1.5-3)$ & $3(2-3)^{*}$ & .20 & $1(1-2)$ & $2(2-3)^{*}$ & .56 & 1.00 & 0.93 & 0.88 & 0.95 & 0.90 & 0.88 \\
\hline Going on vacation & $1(1-1)$ & $1(1-1)$ & & $2(1-2)$ & $3(2-3)^{*}$ & .52 & 1.00 & 0.97 & 1.00 & 0.97 & 1.00 & 0.86 \\
\hline
\end{tabular}

Going on vacation $1(1-1) \quad 1(1-1)$

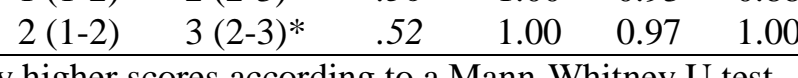

${ }^{\mathrm{a}}$ Frequency levels were scored as follows: never $=0$, less than monthly $=1$, monthly $=2$, weekly $=3$, daily $=4$ 
${ }^{\mathrm{b}}$ Engagement levels were scored as follows: not at all $=0$, a little $=1$, fairly $=2$, very $=3$

${ }^{\mathrm{c}} \mathrm{M}$, F and S stands for Mother, Father and Sibling(s)

${ }^{\mathrm{d}}$ In the calculation of group proportions, the denominator is determined by the amount of activities with a reported frequency higher than zero corrected for missing data and the possible presence of the specific family member

${ }^{\mathrm{e}}$ Effect sizes $|r|$ are calculated by dividing the Z-statistic by the square root of $N$ and only displayed in case of a statistically significant betweengroup difference 
Table 3

Diversity of Family Activities on Category Level in the DD-group and the TD-group

\begin{tabular}{lllllll}
\hline Diversity & \multicolumn{2}{c}{ DD } & & \multicolumn{2}{c}{ TD } \\
\cline { 2 - 3 } \cline { 5 - 6 } & Mean $(S D)$ & $\begin{array}{c}\text { Mean } \\
\text { proportion }^{\mathrm{a}}\end{array}$ & & Mean $(S D)$ & $\begin{array}{c}\text { Mean } \\
\text { proportion }^{\mathrm{a}}\end{array}$ & $|r|^{\mathrm{b}}$ \\
\hline Indoor activities $(n=18)$ & $10.65(3.46)$ & .60 & & $13.58(2.32)^{*}$ & .75 & .45 \\
Meals $(n=7)$ & $4.29(2.28)$ & .61 & & $6.18(1.34)^{*}$ & .88 & .45 \\
Routines $(n=8)$ & $6.16(1.89)$ & .77 & & $7.80(0.59)^{*}$ & .98 & .51 \\
Outdoor activities $(n=11)$ & $5.98(2.58)$ & .55 & & $8.76(2.20)^{*}$ & .80 & .51 \\
Organized activities $(n=4)$ & $1.49(1.19)$ & .37 & & $1.44(1.18)$ & .36 & .28 \\
Outings $(n=10)$ & $7.29(1.63)$ & .73 & & $8.18(1.44)^{*}$ & .82 & .28 \\
\hline
\end{tabular}

${ }^{*} p<.05$; the asterix is placed with the group that reported significantly higher scores according to a Mann-Whitney $U$ test

${ }^{a}$ The mean number of activities is divided by the total number of activities within the category, corrected for missing data

${ }^{\mathrm{b}}$ Effect sizes $|r|$ are calculated by dividing the $Z$-statistic by the square root of $N$ and only displayed in case of a statistically significant between-

group difference 
Table 4

Frequency of Family Activities on Category Level in the DD-group and the TD-group

\begin{tabular}{|c|c|c|c|c|c|c|}
\hline \multirow[t]{2}{*}{ Frequency } & \multicolumn{2}{|c|}{ Mean $(S D)^{\mathrm{a}}$} & \multirow[t]{2}{*}{$|r|^{\mathrm{c}}$} & \multicolumn{2}{|c|}{ Corrected Mean $(S D)^{\mathrm{b}}$} & \multirow[t]{2}{*}{$|r|^{c}$} \\
\hline & DD & TD & & DD & TD & \\
\hline Indoor activities & $1.95(0.64)$ & $2.47(0.41)^{*}$ & .43 & $3.31(0.38)$ & $3.29(0.32)$ & \\
\hline Meals & $2.25(1.27)$ & $3.19(0.78)^{*}$ & .37 & $3.62(0.48)$ & $3.60(0.34)$ & \\
\hline Routines & $2.85(0.90)$ & $3.68(0.34)^{*}$ & .49 & $3.69(0.25)$ & $3.78(0.16)$ & \\
\hline Outdoor activities & $1.29(0.73)$ & $2.19(0.71)^{*}$ & .54 & $2.34(0.74)$ & $2.71(0.44)^{*}$ & .30 \\
\hline Organized activities & $0.62(0.54)$ & $0.72(0.73)$ & & $1.69(0.69)$ & $1.90(0.80)$ & \\
\hline Outings & $1.39(0.46)$ & $1.71(0.36)^{*}$ & .36 & $1.87(0.42)$ & $2.10(0.35)^{*}$ & .29 \\
\hline
\end{tabular}

${ }^{*} p<.05$; the asterix is placed with the group that reported significantly higher scores according to a Mann-Whitney $U$ test

${ }^{a}$ The sum of frequency scores is divided by the total amount of questioned activities within the category, corrected for missing data

${ }^{\mathrm{b}}$ The sum of frequency scores is divided by the amount of activities with a reported frequency higher than zero (which automatically also corrects for missing data)

${ }^{\mathrm{c}}$ Effect sizes $|r|$ are calculated by dividing the Z-statistic by the square root of $N$ and only displayed in case of a statistically significant betweengroup difference 
Table 5

Child Engagement in Family Activities on Category Level in the DD-group and the TD-group

\begin{tabular}{lccc}
\hline \multirow{2}{*}{ Child engagement } & \multicolumn{2}{c}{ Mean $(S D)^{\mathrm{a}}$} & \\
\cline { 2 - 3 } & $\mathrm{DD}$ & $\mathrm{TD}$ & $|r|^{\mathrm{b}}$ \\
\hline Indoor activities & $1.48(0.54)$ & $2.33(0.34)^{*}$ & .71 \\
Meals & $0.96(0.84)$ & $1.96(0.50)^{*}$ & .60 \\
Routines & $1.27(0.76)$ & $2.01(0.52)^{*}$ & .50 \\
Outdoor activities & $1.30(0.69)$ & $2.30(0.57)^{*}$ & .62 \\
Organized activities & $1.22(0.80)$ & $2.07(0.72)^{*}$ & .48 \\
Outings & $1.31(0.61)$ & $2.43(0.47)^{*}$ & .73 \\
\hline
\end{tabular}

${ }^{*} p<.05$; the asterix is placed with the group that reported significantly higher scores according to a Mann-Whitney $U$ test

${ }^{a}$ The sum of engagement scores is divided by the amount of activities with a reported frequency higher than zero, corrected for missing data

${ }^{\mathrm{b}}$ Effect sizes $|r|$ are calculated by dividing the Z-statistic by the square root of $N$ and only displayed in case of a statistically significant betweengroup difference 
Running Head: FAMILY ACTIVITIES AND CHILD ENGAGEMENT

Table 6

Family member's presence in family activities on category level in the DD-group and the TD-group

\begin{tabular}{|c|c|c|c|c|c|c|c|c|}
\hline \multirow[t]{2}{*}{ Presence } & \multicolumn{2}{|c|}{$\begin{array}{l}\text { One parent } \\
\text { Mean }(S D)^{\mathrm{a}}\end{array}$} & \multicolumn{2}{|c|}{$\begin{array}{l}\text { Two parents } \\
\text { Mean }(S D)^{\mathrm{a}}\end{array}$} & \multicolumn{2}{|c|}{$\begin{array}{c}\text { Only sibling(s) } \\
\text { Mean }(S D)^{\mathrm{a}}\end{array}$} & \multicolumn{2}{|c|}{$\begin{array}{c}\text { Parent(s) and sibling(s) } \\
\text { Mean }(S D)^{\mathrm{a}}\end{array}$} \\
\hline & DD & TD & $\mathrm{DD}$ & TD & DD & TD & $\mathrm{DD}$ & TD \\
\hline Meals & $.17(.20)$ & $.27(.09)$ & $.35(.10)$ & $.35(.06)$ & $.00(.00)$ & $.00(.00)$ & $.66(.28)$ & $.64(.13)$ \\
\hline Routines & $.24(.14)$ & $.26(.14)$ & $.39(.10)$ & $.36(.09)$ & $.00(.01)$ & $.00(.00)$ & $.51(.13)$ & $.64(.16)$ \\
\hline Outdoor activities & $.21(.13)$ & $.21(.14)$ & $.24(.13)$ & $.32(.17)$ & $.09(.13)$ & $.06(.07)$ & $.59(.18)$ & $.66(.14)$ \\
\hline Outings & $.05(.06)$ & $.13(.13)$ & $.27(.15)$ & $.37(.08)$ & $.00(.00)$ & $.00(.00)$ & $.88(.19)$ & $.81(.14)$ \\
\hline
\end{tabular}

${ }^{a}$ The mean and standard deviation of the group proportions on item level are reported for each category. In the calculation of the group proportions on item level, the denominator is determined by the amount of activities with a reported frequency higher than zero corrected for missing data and the possible presence of a (combination of) family member(s) 